\title{
Study on the Independent Innovation Encouragement Mechanism for College Technology Talents
}

\author{
Yanping Liu \& Chunyan Chen \\ College of Marxism, Changchun University of Science and Technology \\ Changchun 130022, China \\ E-mail: lyp@cust.edu.cn
}

\begin{abstract}
In the time of knowledge economy, the growth and innovation of knowledge are being the essential driving force to form the new formation of economic development and the social advancement. As the important base of basic innovation, colleges should exert the function of fresh troops in the tide of independent innovation. By using the foreign college technology talents innovation encouragement mechanism for references, based on China's actual conditions, we need actively to cultivate the innovation spirit and strengthen the policy support of the government for the college technology innovations in the big environment, and in the small environment such as colleges, we need really establishing the technology talents' oriented management concept, reasonably planning and constructing the scientific research echelon, and establishing the fair income distribution system.
\end{abstract}

Keywords: Colleges, Technology talents, Independent innovation, Encouragement mechanism

In the day, people are entering into the society of knowledge economy, and the growth and innovation of knowledge are being the essential driving force to form the new formation of economic development and the social advancement. As the important base of basic innovation and the important headspring of technology innovation, colleges should exert the function of fresh troops in the tide of independent innovation. But for a long term, the independent innovation of college technology talents has still stayed publicly, and in the organization system, a kind of effective encouragement mechanism which could completely encourage college technology talents' working enthusiasm of independent innovation is deficient. Facing the challenge of knowledge economy and the calling of technology innovation, a set of technology innovation encouragement mechanism suiting for Chinese college technology talents' characteristics should be researched and constructed consciously to drive China to more actively face the increasingly drastic technology competition.

\section{Connotation of the innovation encouragement mechanism}

Encouragement means inspiring, promoting, and exciting. The specialist in organizational behaviors of US, Stephen P. Robbins defined the encouragement as the will to realize the targets of the organization by high-level endeavor which could satisfy individual's certain requirements. Therefore, in the research of encouragement, the human being should be the center of the management activity to pursue the humanity of the management activity. The encouragement mechanism means a set of rational system behavior mode established by the encouragement factors between the subject and the object in the organization system. The target to establish the encouragement mechanism in the college technology innovation is to pursue the balance of the humanity and system in the management activity. Therefore, the technology innovation encouragement mechanism of college can be defined as to follow certain encouragement principle in the interior and exterior of the college, design proper encouragement system and create necessary cultural environment, use the encouragement method to lead, encourage, and standardize technology talents' motivation and behavior to realize the technology innovation in colleges and satisfy individual's demands.

\section{Foreign successful experiences in the researches of the college technology talents innovation encouragement mechanism}

In foreign countries, US first proposed and studied the college technology talents' behavior management as the scientific problem. At that time, the academes in about twenty universities with high reputation in US had been the most excellent places to cultivate technology talents and implement scientific research, which was related with the exploration research about the college technology talents independent innovation encouragement mechanism in US. From construction to now, the technology innovation encouragement mechanism in foreign universities has about 200 years' history, which could not only effectively drive the modern transformation of the college function in western developed countries, but largely drive the technology innovation in west countries. 
Foreign experiences about college technology talent independent innovation encouragement have revealed follows aspects.

First, the construction of talent group should avoid close breeding, pay more attention to the internationalization degree of the teacher group, emphasize the pro-service cultivation, after-service specialty development, and the occupational career planning, and strengthen the successive talent construction in the innovation team and the innovation base.

Second, the culture innovation should encourage adventure, advocate innovation, pursue excellence, and permit failure. Many colleges would rather prize those persons who will take risks and actively participate in the project, but not support those scholastics. The tolerance of failure could largely inspire technology talents' innovational enthusiasm.

Third, the sufficient reward encouragement should be implemented. In the colleges of west developed countries, the scientific assessment and evaluation index system has been established, and high rewards and salaries have not been grudged. So these technology talents in west colleges always satisfy their salaries, which could better encourage them to exert their working potentials.

\section{Actively constructing the college technology talents independent innovation encouragement mechanism fitting for China}

After founding a state, China has always highly emphasized the development and innovation of technology, and Deng Xiaoping proposed that "Science and technology are the primary productive forces", and Jiang Zemin emphasized that "we must strengthen our attitude toward the national innovation ability because it decides our nations prosperity". In the Fifth Session of the Ninth NPC, the premier Zhu Rongji specially emphasized that "to set up and develop the technology innovation encouragement mechanism". Combining with the existing college technology talent innovation encouragement mechanism in west developed countries, based on the actuality of the college technology talents in China, the technology talent independent innovation encouragement mechanism suiting for Chinese colleges should be explored and constructed from two layers, i.e. the big environment and the small environment.

In the big environment, following aspects should be emphasized.

First, the innovation spirit should be cultivated actively. The national characteristic of the Chinese ethnic peoples includes "playing safe and being quiet", which could not only make the Chinese ethnic peoples to like peace and hate wars, but also make them to take things as they are and lack in innovational enthusiasm and impulse. In addition, Chinese people like judging a hero by victory or defeat, so behind "playing safe", Chinese people still have the mentality fearing mistakes and adventures. Therefore, the college technology talent independent innovation encouragement mechanism should be constructed actively, and the national spirit of making bold innovation and willing to innovation should be cultivated in the cultural environment of the whole society, and to bear with failure and encourage adventure could really provide the opening, free, and loose cultural field for innovational talents' innovational endeavors. Furthermore, the independent innovation should not be a kind of consciousness, but also a kind of excellent ability for college technology talents, and this kind of ability mainly comes from technology talents' many years' education. At present, the prominent problem in the education of China is that the innovational power and sprit are deficient. From the education blind deviating from the creative power existing in various layers of education to the learning competition under the existence pressure, from the talent selection management mechanism ignoring innovation to the academic management deviating from the creative rules, the crucial reason revealed in Chinese education system is to bind heart and limit innovation. Therefore, it is a hard project to comprehensively reform the education system of China, and transform from knowledge transfer to ability cultivation, which needs the joint effort of the whole society.

Second, the policy support to the college technology innovation from the government should be strengthened. The technology innovation is a complete system. Vertically, it includes the innovation headspring, the research development, the result transformation, the result conduction radiation, and the innovational result marketization. Horizontally, it includes the centralization and interaction of technology innovation resource factors (such as talent, capital, result, and information) in certain one space and time. Though the college technology innovation could depend on the management platform of college, but the encouragement and orientation function of the government to the technology innovation is irreplaceable. Therefore, the policy support from the government is necessary to construct the technology innovation encouragement mechanism of college. Though China has confirmed the "revitalizing China through science and education" as the development strategy, but to develop the technology and encourage the technology innovation, the financial stimulation policy, the financial support policy, and the patent protection policy should be further strengthened, i.e. the government must construct a protection net of macro control for the technology innovation of college to compensate the deficiency of technology innovation in the market mechanism. 
In the small environment of college, following aspects should be emphasized.

First, the technology talent-oriented management concept should be really established.

Marxism thought that the human being was the most basic, active, and pivotal factor in the productive force and the human resources were the most precious resource in all resources. Therefore, the implementation degree of the college technology innovation is mainly determined by the main body, i.e. the college technology employees' working enthusiasm and creation. However, the obvious tendency of "administration" still exists in the college management system of China, which could not accord with the management requirement of colleges for the cultivation, introduction, use, and encouragement of professional technology talents, and will limit their work enthusiasm, activity, and creativity to some extent. Therefore, to establish the technology talent innovation encouragement mechanism in colleges, the people-oriented management concept should be established first, and the technology talents should be the center of management consciously to emphasize their specialties and respect their individual development, and their constructive potential should be dug comprehensively, and the active function of the encouragement system should be grasped flexibly, and the human resource waste induced by the misfeasance should be fully eliminated.

Second, the scientific research echelon should be reasonably planed and constructed.

The technology innovation can't do without individual innovation spirit and competitive spirit, but any scientific research could not be realized only depending on individual endeavors, so the scientific research echelon must be reasonably planed and constructed for colleges, and the difficulties in the scientific research must be overcame by the collective intelligence. In the scientific research echelon, talents' age structure, title structure, specialty structure should be scientific and reasonable to establish firm base for the cooperation, and their team spirit should be cultivated actively, and they should form strong identification sense and friendly sense of belonging to the scientific research team. At present, the scientific research echelons in many colleges of China are unworthy of the name, and the interior interest fight and nervous human relationship make many people to be in the team only namely, and the actual scientific research only depends on "single endeavor", which is seriously restraining the output of research result with high level. Therefore, not only the scientific research echelon should be reasonably planed and constructed, but also talents' positions should be confirmed, and their behavior values should be emphasized to help them obtain their individual success in the work.

Third, the fair income distribution system should be established to avoid the "Matthew Effect" in the academic circles.

The "Matthew Effect" first occurred in "the Bible", and it means the result of "the poor becomes poorer, and the richer becomes richer" in a kind of unfair social rule at present. In the day, the "Matthew Effect" in the academic circles has been increasingly obvious, i.e. because of the existing academic reputation and status, the academic authorities could easily obtain many reputations and advantages, but common research workers are difficult to obtain supports when they apply for the project, and the polarization between the rich and the poor becomes more and more obvious in the academic circles. The brain drain in colleges of China is very serious, and one of important reasons is low income. The distribution mode of "earning income by identity" and "promoting by seniority" in the past planned economic system still works in colleges, and this income system not only lacks in the competitive force, but also lacks in the competitive encouragement. So it is imperative to establish the distribution system suiting for the construction of the talent group. The key of the distribution system reform is the fair. According to the survey, college teachers' sense about the exterior fairness, the interior fairness, and the individual fairness of the income is very lower, so colleges should actively reform the income system, and further explore the reasonable proportion of the post salary, the grade salary, and the performance salary, which could not only draw away the income gap among different posts and technical talents in the scientific research team, but also guarantee the encouragement power to both key talents and teachers with common employees.

\section{References}

Du, Wei. (2002). Three System Layers of the Technology Innovation Encouragement Mechanism. Research of Party Construction, No.6.

Lv, Jun \& Hou, Jundong. (2006). Construction of the Technology Innovation Encouragement Mechanism in Colleges. Science \& Technology Progress and Policy, No.11.

Lv, Qinyong. (2004). Study on the College Technology Innovation Encouragement Mechanism. Master's degree paper of Xi' an University of Science and Technology, April 25.

Rui, Mingjie. (1999). Management: Modern Opinions. Shanghai: Shanghai People's Publishing House.

Su, Dongshui. (1998). Management Psychology. Shanghai: Shanghai Fudan University Press. 